\title{
CHARACTERIZATION OF FIVE MEMBERS OF THE ACTIN GENE FAMILY IN THE SEA URCHIN
}

\author{
PAUL A. OVERBEEK *, GLENN T. MERLINO **, N. KENT PETERS, VIVIAN H. COHN, GORDON P. MOORE and LEWIS J. \\ KLEINSMITH *** \\ Division of Biological Sciences and Graduate Program in Cellular and Molecular Biology, The University of Michigan, Ann Arbor, \\ MI 48109 (U.S.A.)
}

(Received May 14th, 1981)

Key words: Actin gene; Genome organization; Repetitive DNA; Restriction map; (Sea urchin)

Hybridization of an actin cDNA clone (pSA38) to restriction enzyme digests of Strongylocentrotus purpuratus DNA indicates that the sea urchin genome contains at least five different actin genes. A sea urchin genomic clone library was screened for recombinants which hydridize to pSA38 and four genomic clones were isolated. Restriction maps were generated which indicate that three of these recombinants contain different actin genes, and that the fourth may be an allele to one of these. The restriction maps suggest that one clone contains two linked actin genes. This fact, which was confirmed by heteroduplex analysis, indicates that the actin gene family may be clustered. The linked genes are oriented in the same direction and spaced about 8.0 kilobases apart. In heteroduplexes between genomic clones two intervening sequences were seen. Significant homology is confined to the actin coding region and does not include any flanking sequence. Southern blot analysis reveals that repetitive DNA sequences are found in the region of the actin genes.

\section{Introduction}

Actin is an abundant protein in most eukaryotic cell types. It plays an important role in many forms of motility including muscle contraction, chromosome movement, cytokinesis, exocytosis and phagocytosis (reviewed, e.g., in Ref. 1). In mammalian systems, at least three different forms of actin have been identified by two-dimensional electrophoresis. The most acidic form, $\alpha$-actin, appears to be musclespecific, while the other two forms are cytoplasmic and appear to be present in all cells [2-5]. Sequencing studies indicate that the three actins have similar

\footnotetext{
* Present address: University of Chicago, Chicago, IL 60637 , U.S.A.

** Present address: Laboratory of Molecular Biology, National Cancer Institute, Bethesda, MD 20205, U.S.A.

*** To whom correspondence should be addressed.

Abbreviation: SSC, $0.15 \mathrm{M}$ sodium chloride/0.015 $\mathrm{M}$ trisodium citrate.
}

amino acid sequences, but are products of separate genes [6]. Multiple forms of actin protein have also been found in Drosophila [7], Dictyostelium [8] and sea urchin [9]. Actin genes have now been cloned from a wide variety of organisms including Dictyostelium [8], Drosophila [10-12], Saccharomyces $[13,14]$ chicken $[15]$, sea urchin $[9,16,17]$ and man [18].

We have published the results of recent experiments which suggest that expression of the actin gene family in sea urchin is under strict developmental control. The amount of actin mRNA, which is very low in oocytes, increases dramatically $12-18 \mathrm{~h}$ after fertilization. Further, there are two different actin mRNAs (2.0 and 2.3 kilobases) which appear to be regulated differentially [19]. In order to initiate a detailed study of the molecular basis of the regulation of sea urchin actin gene expression, a Strongylocentrotus purpuratus library was screened for actin-containing clones with a previously characterized [9] actin cDNA probe. This communication describes the 
isolation and initial characterization of four recombinants, containing at least four different sea urchin actin genes. We report the interesting observation that two of the actin genes are physically linked. In conjunction with data from other laboratories, this finding suggests the possibility that the entire actin gene family may be clustered in the sea urchin genome.

\section{Materials and Methods}

Screening. A genomic library constructed using DNA from an individual $S$. purpuratus cloned in phage $\lambda$ as described by Maniatis et al. [20], was kindly provided by the laboratory of E.H. Davidson and R.J. Britten. The actin cDNA clone, pSA38, used to screen the phage $\lambda$ library was constructed by insertion of cDNAs into the BamHI site of pBR322 using BamHI linkers. The cDNA insert size was found to be 1.5 kilobases clockwise from the BamHI site; furthermore, approximately 1.1 kilobases of pBR322 DNA have been deleted irom this region, and thus only one BamHI site remains in the plasmid. A complete description of the construction, isolation and characterization of pSA38 has been previously described [9]. pSA38 was labelled to a specific activity of approx. $5 \cdot 10^{7}$ with ${ }^{32} \mathrm{P}$ according to the nicktranslation method of Rigby et al. [21]. A modification of the plaque hybridization technique described by Benton and Davis [22] was used to screen the sea urchin library for recombinant phage containing DNA complementary to the sea urchin actin cDNA clone. Plaques were transferred by absorption onto duplicate sterile nitrocellulose filters (Schleicher and Schuell BA85). The phage DNAs were denatured and fixed by immersing each filter for $20 \mathrm{~s}$ in each of the following solutions: $0.1 \mathrm{~N} \mathrm{NaOH} ; 1.5 \mathrm{M} \mathrm{NaCl}$; and 0.2 M Tris- $\mathrm{HCl}\left(\mathrm{pH} \mathrm{7.5).} \mathrm{After} \mathrm{baking} \mathrm{at} 80^{\circ} \mathrm{C}\right.$ for 90 $\mathrm{min}$, the filters were presoaked for $30-60 \mathrm{~min}$ at $65^{\circ} \mathrm{C}$ in $300 \mathrm{ml} 1 \%$ Sarkosyl-5XSSC. The filters were then transferred to a heat-sealed plastic bag and hybridized with denatured, nick-translated $\Gamma^{32} \mathrm{P} \mid p S A 38$ $\left(5 \cdot 10^{5} \mathrm{cpm} /\right.$ filter $)$ in $6-10 \mathrm{ml} 1 \%$ Sarkosyl-5XSSC at $65^{\circ} \mathrm{C}$ for $20 \mathrm{~h}$. After hybridization, the filters were washed twice with $150 \mathrm{ml} 0.5 \%$ Sarkosyl-3XSSC, 30 min at $65^{\circ} \mathrm{C}$, and twice with $150 \mathrm{ml} 3 \times \mathrm{SSC}, 20 \mathrm{~min}$ at $65^{\circ} \mathrm{C}$. Autoradiograms were exposed at $-70^{\circ} \mathrm{C}$ using Kodak X-Omat R X-ray film and a Kodak C-2 film cassette equipped with Dupont Lightening Plus intensification screens. Positive plaques were picked and rescreened. Pretreatment and hybridization in $1 \%$ Sarkosyl was found to give lower background than analogous treatment with $10 \times$ Denhardt's solution.

Restriction endonuclease digestions, agarose gel electrophoresis, and Southern transfers. The recombinant phage which hybridized to pSA38 were propagated as described by Blattner in the protocol provided with the Charon 4 cloning vector. Restriction endonuclease digestions were performed for $60 \mathrm{~min}$ at $37^{\circ} \mathrm{C}$ using a 10 -fold excess of enzyme in the buffers suggested by the suppliers (New England Biolabs and BRL). Digested DNAs $(0.1-0.4 \mu \mathrm{g}$ for phage DNAs; $1.4-2.0 \mu \mathrm{g}$ for genomic DNAs) were electrophoresed at $100 \mathrm{~V}$ for $3 \mathrm{~h}$ in horizontal $0.7 \%$ agarose gels (3-mm thickness) in $50 \mathrm{mM}$ Tris $/ 20 \mathrm{mM}$ sodium acetate $/ 2 \mathrm{mM}$ EDTA $/ 18 \mathrm{mM} \mathrm{NaCl}$, adjusted to $\mathrm{pH}$ 8.5 using glacial acetic acid [23]. Eco RI and HindIII digests of $\lambda$ DNA were included in each gel as molecular weight standards. DNA was transferred to nitrocellulose for hybridization with various radioactively labelled DNA probes as described by Southern [24]. Pretreatment and hybridization were carried out using $1 \%$ Sarkosyl-5XSSC as described above.

Heteroduplex formation and electron microscopy. Heteroduplexes were prepared in $70 \%$ formamide using the procedure of Davis et al. [25], and viewed using either a Zeiss $10 \mathrm{~A}$ or a JEOL JEM 100B electron microscope. Contour lengths were measured using a Numonics digitizer interfaced with a HewlettPackard 9825A computer. SV40 (5.226 kilobases) was used as a length standard for double-stranded DNA; M13 (7.196 kilobases) was used for singlestranded DNA.

\section{Results}

\section{Multi actin genes in the sea urchin genome}

Total sea urchin sperm DNA was digested with various restriction enzymes, fractionated by electrophoresis, transferred to nitrocellulose and hybridized with $\left[{ }^{32} \mathrm{P}\right] \mathrm{pSA} 38$. Fig. $1 \mathrm{~A}$ shows a representative blot after digestion with HindIII. The autoradiogram shows five bands. Several of these bands are broad, suggesting the possibility that they contain more than one hybridizing sequence with similar electrophoretic mobilities. This result, and similar data using other enzymes, implies that there may be as many as five, 

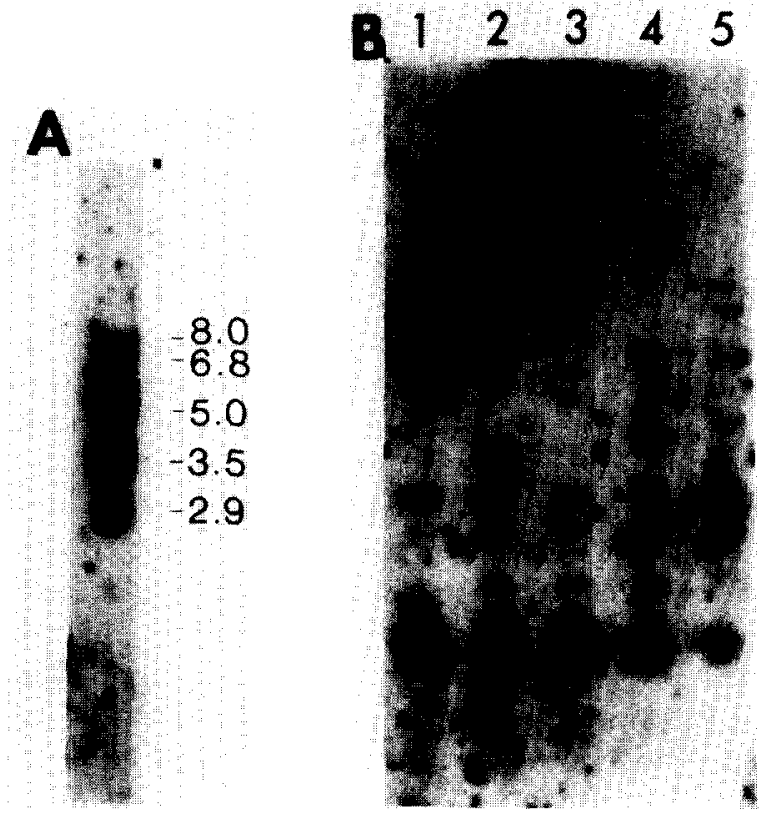

Fig. 1. Actin gene copy number. A. $1.4 \mu \mathrm{g}$ DNA from the sperm of an individual sea urchin was digested with HindIII, electrophoresed through $0.7 \%$ agarose and transferred to nitrocellulose. The blot was hybridized with $\left[{ }^{32} \mathrm{P}\right] \mathrm{pSA38}$ and visualized by autoradiography. Sizes (in kilobases) were estimated by the mobility of the bands relative to that of restricted $\lambda$ DNA. B. $2 \mu \mathrm{g}$ DNA from the sperm of five different individual sea urchins was digested with $\mathrm{HpaII}$; electrophoresis, transfer and hybridization were performed as above.

and possibly more, actin genes in the sea urchin genome. Fig. 1B shows the blot pattern when sperm DNA from five different individual sea urchins was digested with HpaII and reacted with pSA38. Although certain bands are common to all five individuals, the banding pattern is different in every case. Thus the actin gene regions show surprising polymorphism considering the evolutionary conservation of actin protein.

\section{Isolation of sea urchin genomic actin clones}

30000 phage from a sea urchin genomic clone library were screened for homology with the sea urchin actin cDNA clone pSA38. Four recombinants (labelled $\lambda S A 11, \lambda S A 12, \lambda S A 16$ and $\lambda S A 22)$ which hybridize with pSA38 were identified. DNA from each was purified, digested with various restriction enzymes, electrophoresed in agarose gels, transferred to nitrocellulose and reacted with $\left[{ }^{32} \mathrm{P}\right] \mathrm{pSA} 38$. A representative gel and blot are shown in Fig. 2. The recombinants each show different restriction patterns and have sea urchin DNA inserts of 12.5, 13.9, 14.7 and 12.9 kilobases, respectively. Detailed restriction maps of each clone were constructed (Fig. 3); the complete data which established these maps are available elsewhere [26]. A striking point emerging from these maps is that at least two actin genes, namely those found on $\lambda \mathrm{SA} 11$, are linked. The distance between these genes is about 8.0 kilobases. This observation is confirmed by the heteroduplexes shown below and further discussed in the next section.

\section{Heteroduplex analysis}

The clones containing actin genes were further characterized by heteroduplex formation and visualization in the electron microscope. The clones were heteroduplexed with each other and with pSA38. In each case, contour length measurements confirmed the placement of the actin coding regions as shown in the restriction maps of Fig. 3. Flanking region homologies were not observed between $\lambda \mathrm{SA} 11$ and $\lambda \mathrm{SA} 16$, or $\lambda \mathrm{SA} 11$ and $\lambda \mathrm{SA} 22$. This result is consistant with the non-allelism of these actin genes inferred from the restriction maps, and suggests that there are no long homologous sequences flanking these genes. Fig. 4 shows a representative heteroduplex between genomic clones $\lambda$ SA 11 and $\lambda$ SA 16 . The region of homology is about 1.7 kilobases, which is similar to the size of actin mRNA (2.0 and 2.3 kilobases). The somewhat larger size of the mRNAs can be explained by the presence of poly(A) and perhaps non-coding sequences which are not conserved between actin gene family members.

Fig. 5 shows a heteroduplex of linearized pSA38 with $\lambda \mathrm{SA} 11$. As predicted by the restriction map, two actin genes are linked on $\lambda S A 11$. The lengths of the duplexed regions are about 1.2 and 0.8 kilobases, respectively, suggesting that one of the genes may be more closely related to pSA38 than the other. The genes are spaced about 8.0 kilobases apart. The nonhybridizing arms of the pSA38 plasmid are asymmetrical. In Fig. 5 it can be seen that the long and short non-hybridizing arms of pSA38 are oriented in the same direction in each of the actin coding regions of $\lambda S A 11$. Thus, we conclude that the two actin 


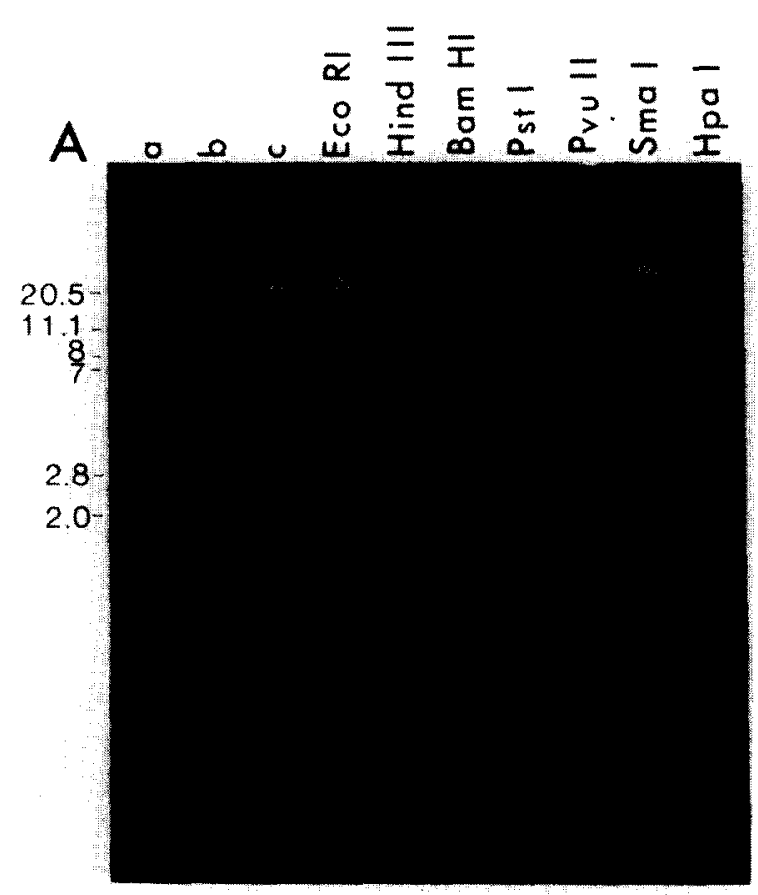

B

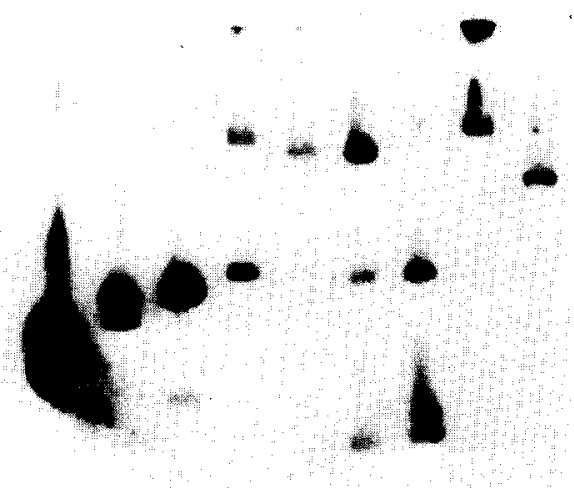

Fig. 2. Mapping the restriction sites in $\lambda$ SA11. A. $0.2 \mu \mathrm{g}$ DNA from $\lambda$ SA11 was digested with various restriction enzymes, fractionated by electrophoresis in $0.7 \%$ agarose, stained with ethidium bromide, then photographed by transilluminated with ultraviolet light. Band lengths were determined as in Fig. 1. B. The DNA was transferred to nitrocellulose, hybridized with $\left[{ }^{32} \mathrm{P}\right] \mathrm{pSA} 38$ and autoradiographed. Lane a, EcoRI digest of Charon 4; lane b, EcoRI digest of pSA38; lane c, EcoRI digest of $\lambda S A 16$. genes have the same $5^{\prime}-3^{\prime}$ orientation.

The direction of transcription of the actin genes was determined in a separate experiment and is shown in Fig. 3. $\left[{ }^{32} \mathrm{P}\right] \mathrm{CDNA}$ was prepared from sea urchin blastulae poly(A)+ mRNA using oligo (dT) primers, reverse transcriptase and a limiting concentration of $\left[\alpha^{32} \mathrm{P}\right] \mathrm{ATP}$ as described by Ullrich et al. [29]. Since synthesis of cDNA from mRNA by reverse transcriptase is frequently incomplete, the $\left[{ }^{32} \mathrm{P}\right] \mathrm{cDNA}$ should be complementary primarily to the $3^{\prime}$ end of the transcripts and the corresponding genes. Direction of transcription was first determined in $\lambda$ SA16. As shown in Fig. 3, EcoRI cuts the actin coding region into two fragments of 3.0 and 3.6 kilobases. When $\lambda \mathrm{SA} 16$ was digested with $E c o$ RI, electrophoresed, transferred to nitrocellulose and hybridized with $\left[{ }^{32} \mathrm{P}\right] \mathrm{cDNA}$, the 3.6-kilobase EcoRI fragment hybridized but the 3.0-kilobase fragment did not (data not shown). This result indicates the direction of transcription shown in the figure. The direction of transcription of the linked genes in XSA11 was inferred by extrapolation from heteroduplexes with $\lambda$ SA16.

The heteroduplexes shown in Fig. 5 reveal no interrupting of the duplex regions that might indicate the presence of intervening sequences, though it is worth noting that short intervening sequences (less than 200 base pairs) are difficult to visualize in the electron microscope. In other heteroduplexes, however, intervening sequences could be seen. Examples are heteroduplexes between $\lambda$ SA1 1 and $\lambda S A 16$, and between $\lambda$ SA11 and $\lambda$ SA22, shown in Figs. 4 and 6 , respectively. In Fig. 4, two small intervening sequences are found, one near the $5^{\prime}$ end of the gene and a second near the $3^{\prime}$ end. Fig. 6 shows an intervening sequence near the $5^{\prime}$ end of the gene corresponding to the same position as the $5^{\prime}$ intron in Fig. 4. A possible second intron is seen which corresponds in placement with the $3^{\prime}$ intron shown in Fig. 4. Partial sequencing of two different sea urchin actin genes has revealed intervening sequences at positions 121 and 204 in the amino acid coding sequence $[16,17]$. Estimations of the positions of the introns seen in Figs. 4 and 6 suggest that they are in the same positions relative to the amino acid coding sequence as the intron found in the partially sequenced genes.

Repetitive DNA flanking the actin genes

To assay for repetitive DNA in the sea urchin 

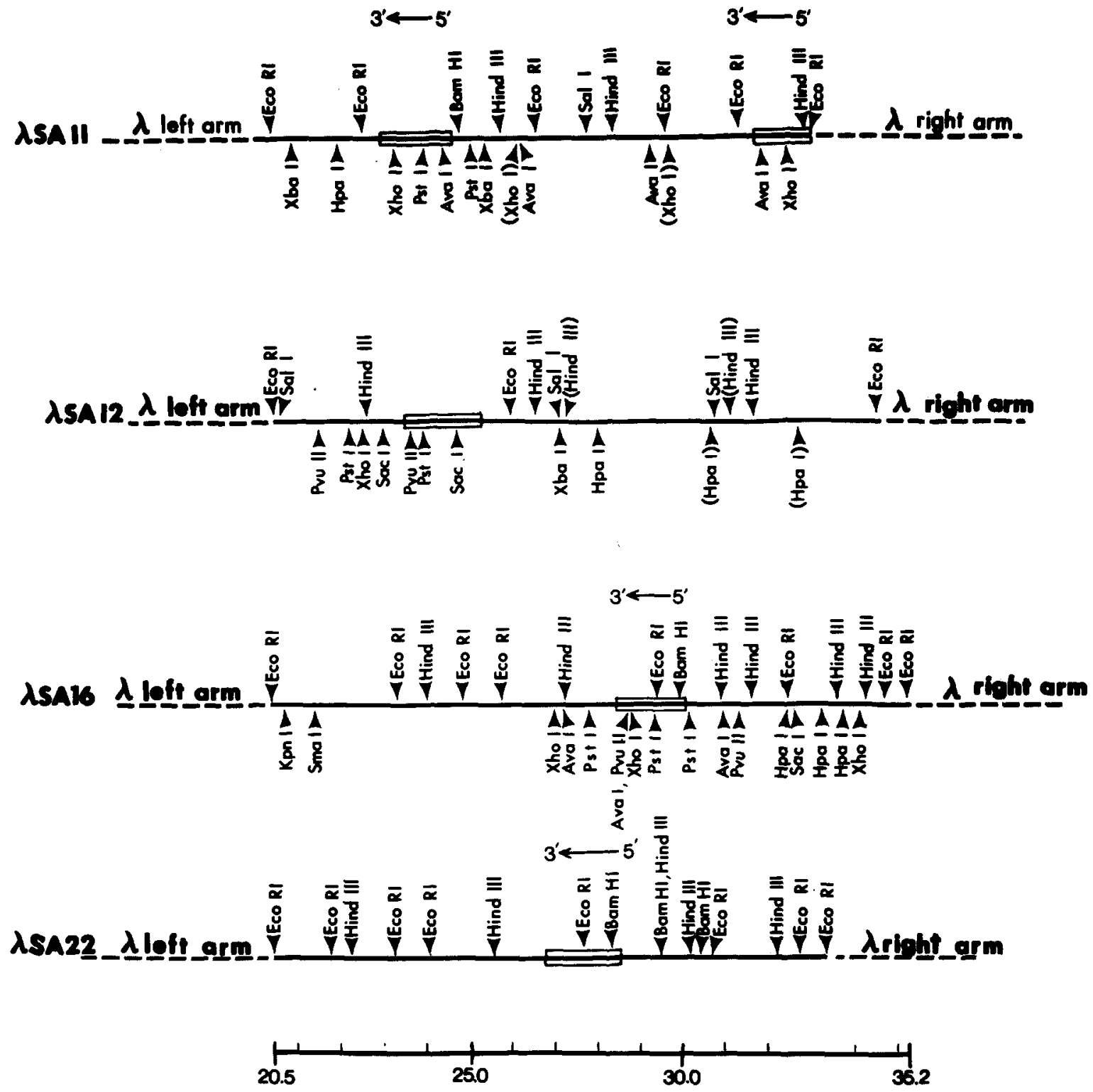

Fig. 3. Restriction maps of $\lambda S A 11, \lambda S A 12, \lambda S A 16$ and $\lambda$ SA22. The solid line in each map represents the sea urchin DNA while the left and right arms of the $\lambda$ vector are indicated by dashed lines. The boxed regions indicate DNA complementary to pSA38, i.e., the actin structural genes. The numbered scale shows the distance in kilobases from the left end of the phage DNA. The $5^{\prime}-3^{\prime}$ orientation of the actin genes in $\lambda$ SA11, $\lambda$ SA16 and $\lambda$ SA22 is indicated. In $\lambda$ SA11, the genomic insert is $12.5 \mathrm{kilobases}$ in length. The actin genes map at 23.0-23.6 and 32.0-33.0 kilobases. The sea urchin DNA in $\lambda$ SA11 is not cut by KpnI, SacI or SmaI. One of the XhoI cleavage sites has not been mapped unambiguously. The two possible locations for the site are enclosed in parentheses. In $\lambda \mathrm{SA} 12$, the genomic insert is 13.9 kilobases in length. The actin coding region maps at $23.5-25.0$ kilobases. The genomic insert in $\lambda \mathrm{SA} 12$ is not cut by SmaI or BamHI. One HpaI cleavage site and one HindIII cleavage site remain ambiguous. In $\lambda S A 16$, the genomic insert measures 14.7 kilobases. The actin gene spans the region from $28.4-30.0$ kilobases. $X b a I$ and Sall do not cleave the cloned DNA. In $\lambda$ SA22, the genomic insert is 12.9 kilobases. The actin gene extends from $26.4-28.7 \mathrm{kilobases}$. Only EcoRI, Bam HI and HindIII digests have been performed. 

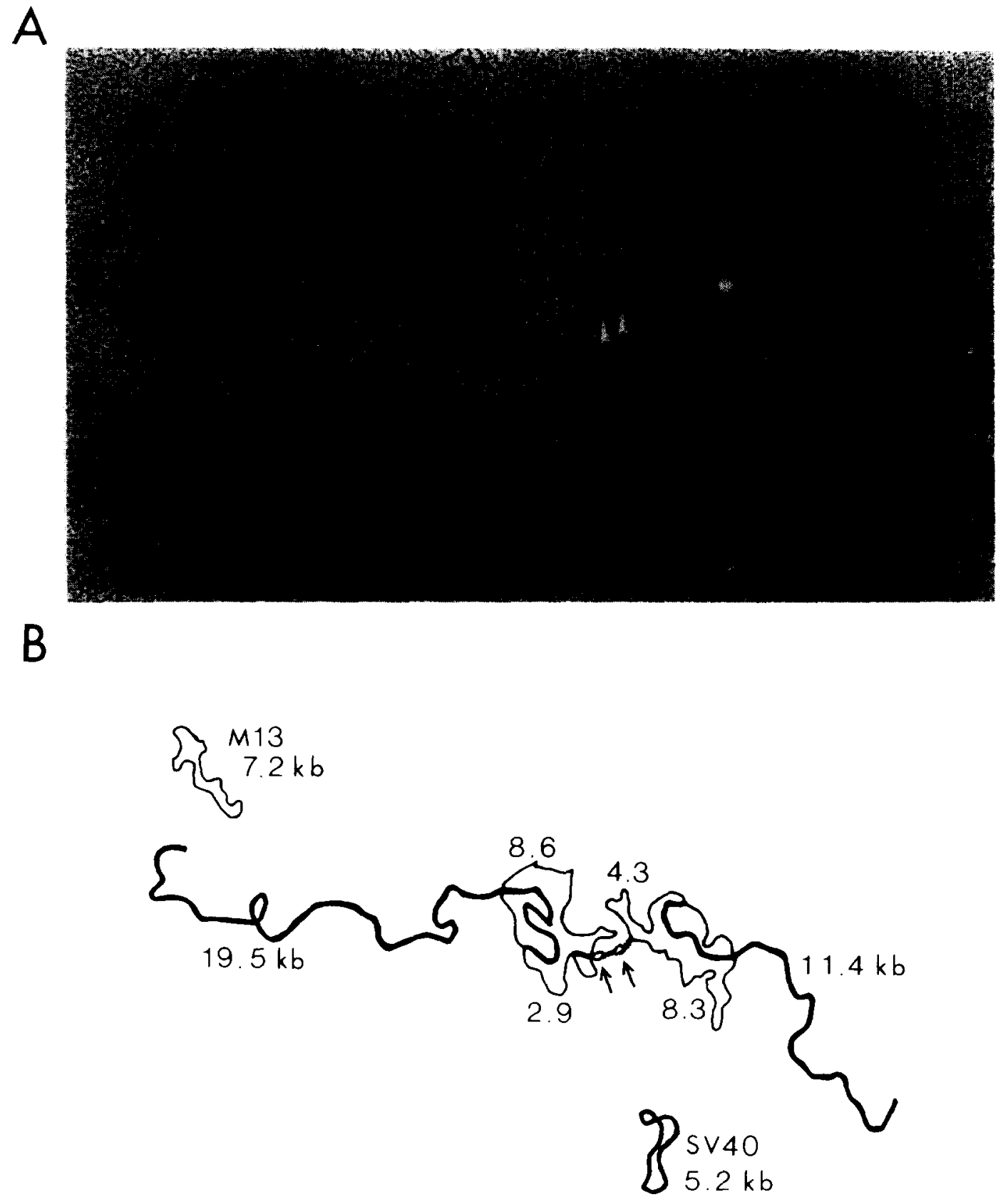

Fig. 4. Heteroduplex of $\lambda S A 11$ with $\lambda$ SA16. A. DNAs from the two clones were heteroduplexed and visualized as described in the Methods section. The arrows point to the regions of non-homology within the actin structural gene. B. A line drawing of the photograph of Fig. 4A showing distances measured in kilobases as described in the Materials and Methods section. The arrows point to the introns corresponding to amino acid positions 121 and 204 . The heteroduplexed region ( $1.7 \mathrm{kilobases}$ in total length) contains three exons of 370,250 and 520 base pairs, respectively, in the $5^{\prime}$ to $3^{\prime}$ direction, and two introns of 250 and 300 base pairs, respectively. 


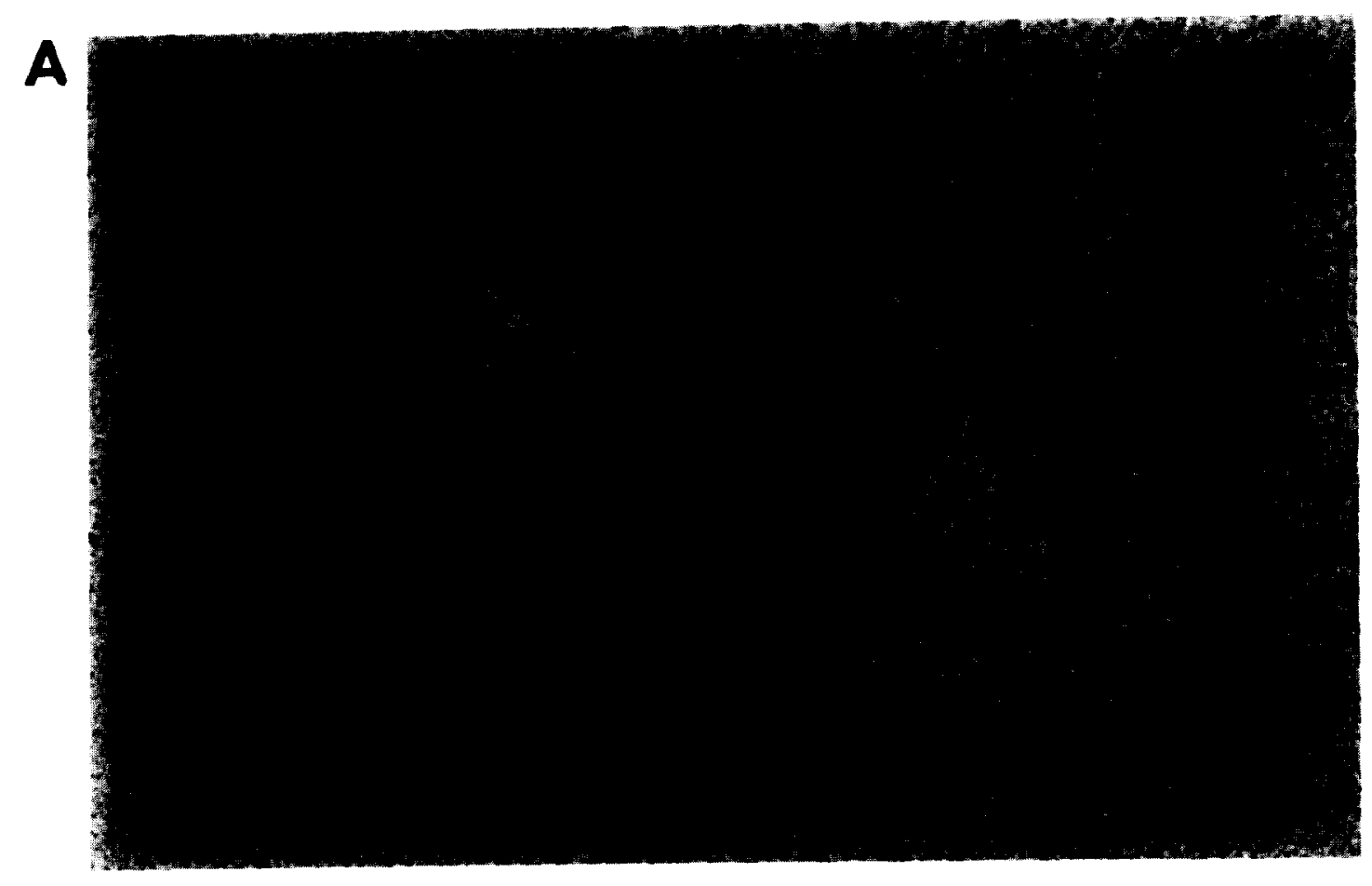

B

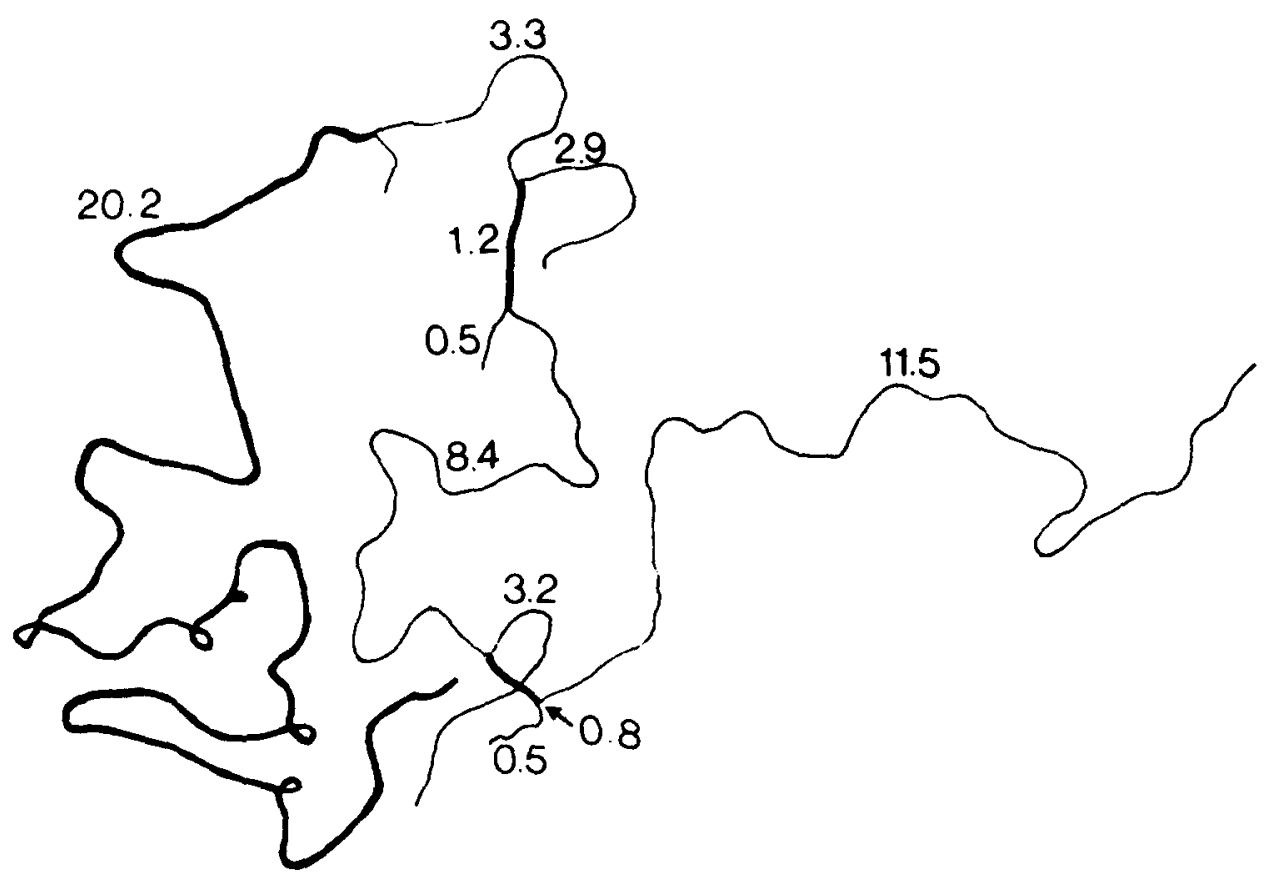

Fig. 5. Heteroduplex of $\lambda S A 11$ with pSA38. A. DNA from $\lambda$ SA11 was heteroduplexed to DNA from the actin cDNA containing plasmid pSA38 linearized with EcoRI. Annealing and visualization were performed as described in the Materials and Methods section. B. A line drawing of the photograph of Fig. 5A showing the position of the two actin genes linked in $\lambda$ SA11. Lengths were determined as described in the Materials and Methods section. One of the phage arms has duplexed with a broken phage arm from another phage. 


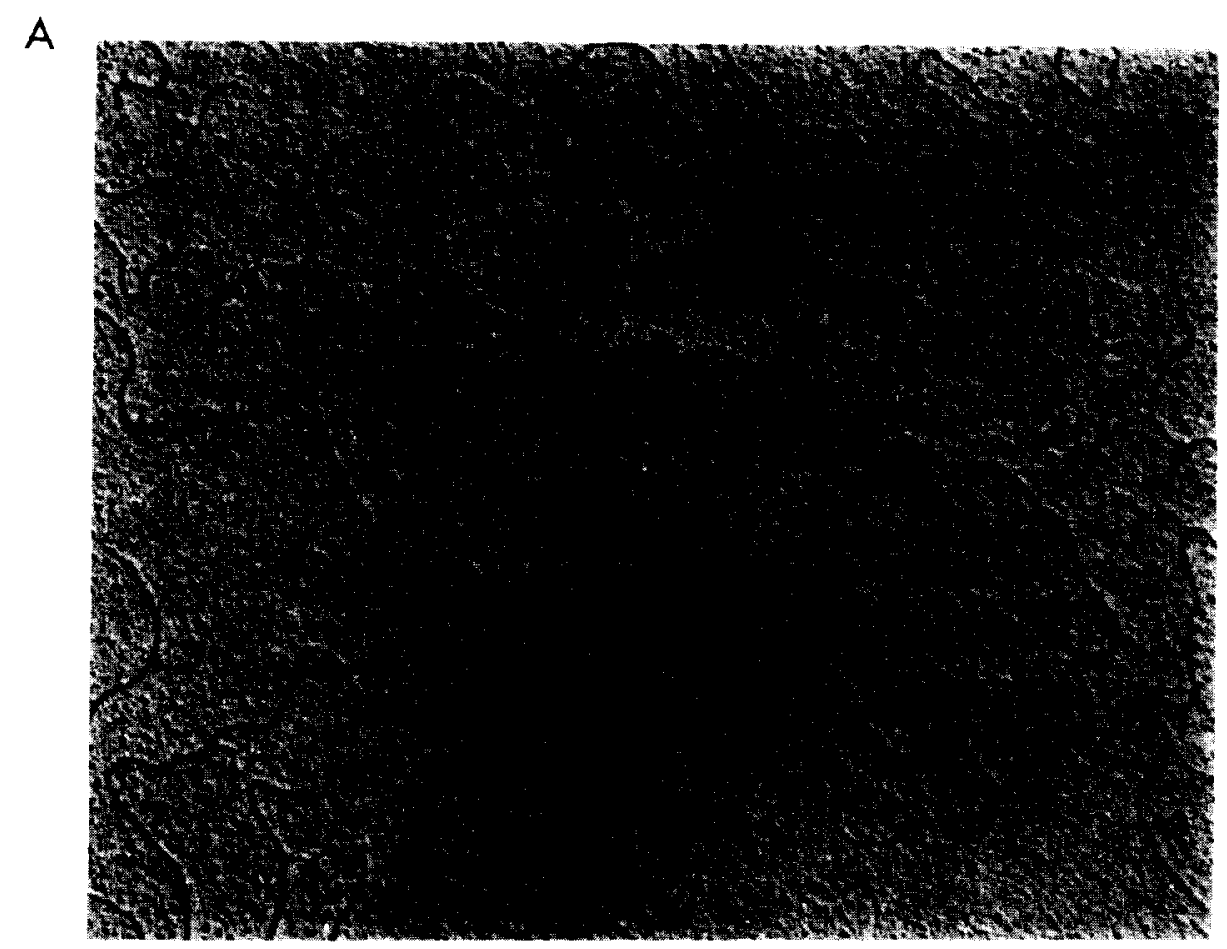

B

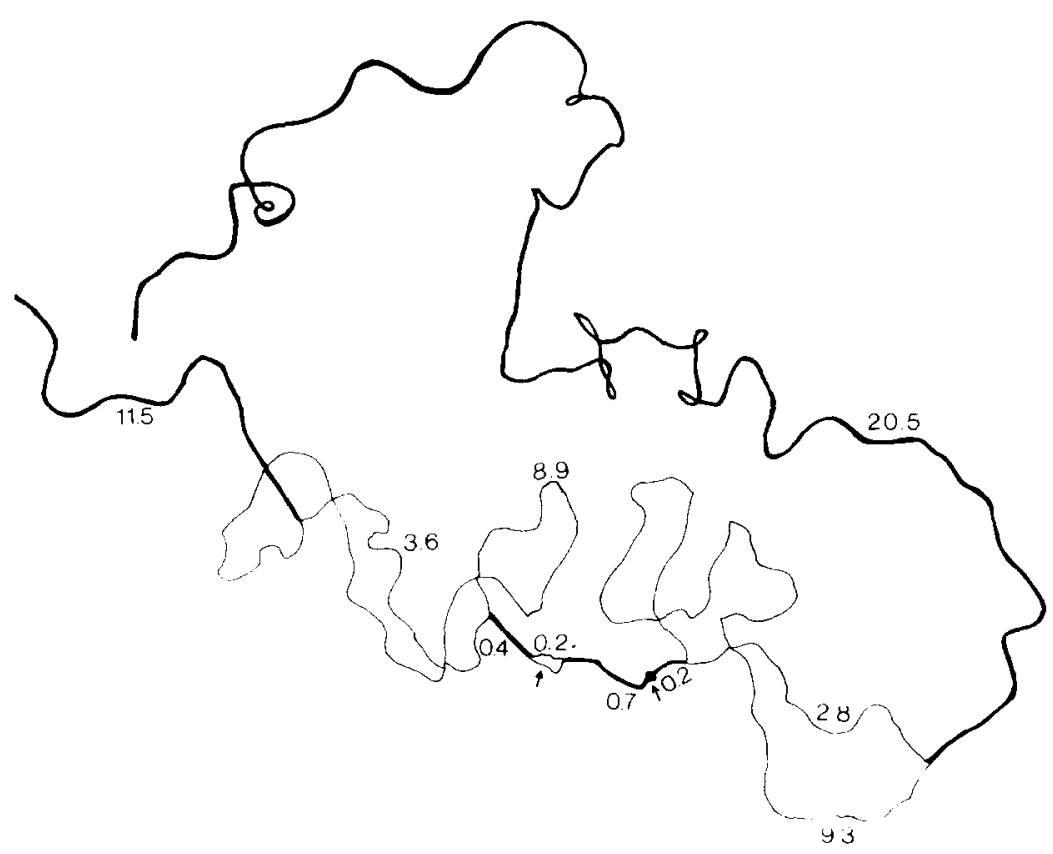

Fig. 6. Heteroduplex of $\lambda$ SA11 with $\lambda$ SA22. A. DNAs from the two clones were heteroduplexed and visualized as described in the Materials and Methods section. B. A line drawing of the photograph in Fig. 6A showing distances measured in kilobases as described in the Materials and Methods section. The left arrow points to the intron corresponding to amino acid position 121 , and the right arrow points to the discontinuity which may represent a second intervening sequence. 


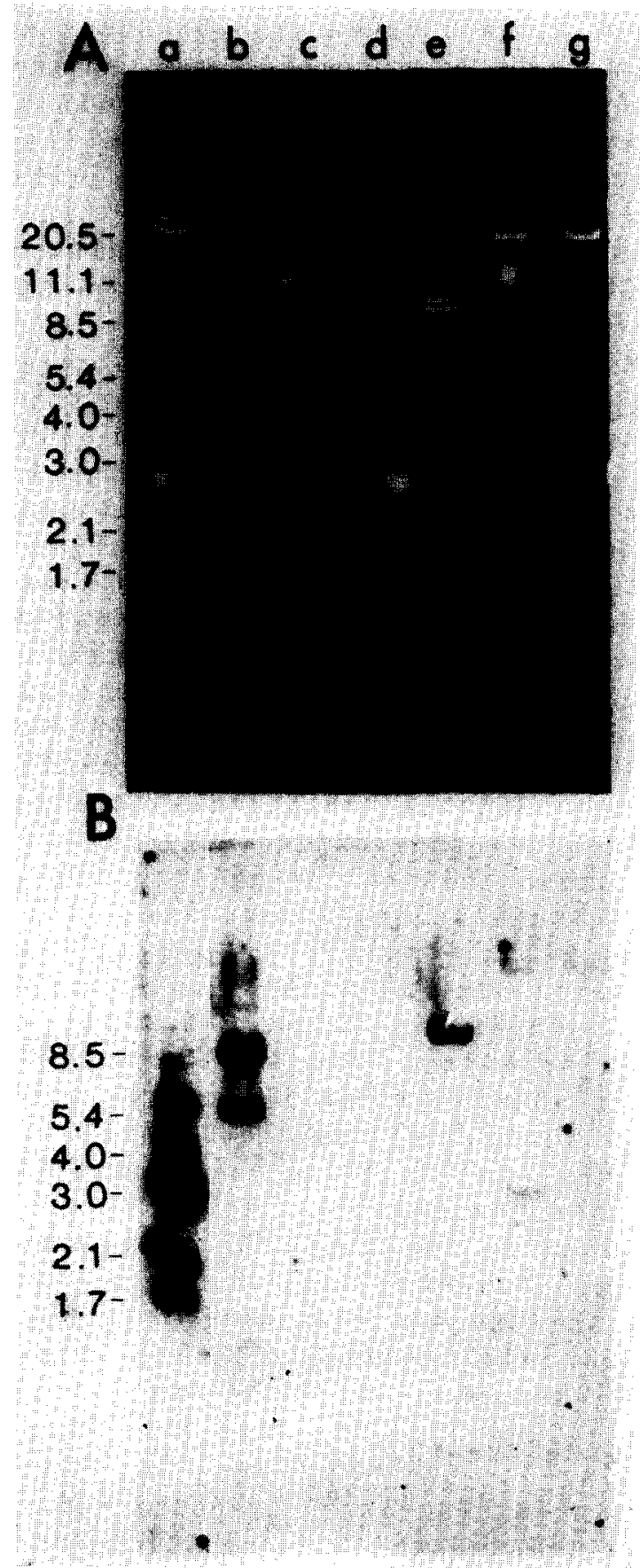

Fig. 7. Repetitive DNA in the region of the actin structural genes. A. $0.2 \mu \mathrm{g}$ DNA from the actin-containing $\lambda$ clones and markers was digested with various restriction enzymes, electrophoresed through $0.7 \%$ agarose, stained with ethidium bromide and photographed in ultraviolet light. B. The DNAs were transferred to nitrocellulose, hybridized with ${ }^{32} \mathrm{P}$ - inserts of $\lambda$ SA11, $\lambda S A 12$ and SA16, the clones were digested with various restriction enzymes, fractionated by electrophoresis, transferred to nitrocellulose and hybridized with nick-translated ${ }^{32}$ P-labelled sea urchin genomic DNA. When radioactively labelled total genomic DNA is hybridized to cloned genomic fragments, the intensity of hybridization bands provides qualitative information about the genomic repeat frequency of the sequences present in a given fragment. Cloned restriction fragments which contain highly repeated sequences hybridize with a greater fraction of the ${ }^{32} \mathrm{P}$-labelled genomic DNA and thus yield more intense bands. The results are shown in Fig. 7. pSA38 contains the actin structural gene, a sequence itself reiterated greater than five times in the sea urchin genome (see Fig. 1), but in this experiment no hybridization band is visible at the exposure time shown (lane d). In contrast, all the EcoRI fragments of the sea urchin DNA in $\lambda$ SA11 show strong hybridization with ${ }^{32} \mathrm{P}$-labelled genomic DNA (lane a), implying the presence of highly repetitive DNA in each fragment. The 3.0-kilobase fragment, which shows the darkest hybridization band, lies between the two actin genes in $\lambda$ SA 11 .

Both sea urchin EcoRI fragments of $\lambda \mathrm{SA} 12$ (8.5 and 5.4 kilobases) show strong hybridization with the genomic DNA, implying the presence of highly repetitive DNA in this clone as well. However, the PstI, HindIII and BamHI digests of $\lambda$ SA16 (Fig. 7, lanes e-g) suggest that $\lambda$ SA16 does not contain such highly reiterated DNA as $\lambda S A 11$ and $\lambda S A 12$. In an EcoRI digest of $\lambda \mathrm{SA} 16$, the only fragment showing a hybridization band is the 2.9-kilobase fragment (data not shown). This initial analysis of repetitive DNA in the three clones suggests that the genomic organization around actin genes in the sea urchin genome may be different for each gene.

\section{Discussion}

Partial screening of a sea urchin genomic clone library led to the isolation of four recombinant phage

labelled total sea urchin DNA labelled by the nick-translation method, and autoradiographed. Lane a, $\lambda S A 11$ digested with EcoRI; lane b, $\lambda \mathrm{SAl} 2$ digested with $E c o$ RI; lane c, wild-type $\lambda$ digested with HindIII; lane d, pSA38 digested with EcoRI; lanes e-g, $\lambda S A 16$ digested with PstI, HindIII and BamHI, respectively. 
(named $\lambda S A 11, \lambda S A 12, \lambda S A 16$ and $\lambda S A 22$ ), each containing sequences complementary to the sea urchin actin cDNA clone pSA38. Three of these clones $(\lambda S A 11, \lambda S A 12$ and $\lambda S A 16)$ are clearly non-allelic because they exhibit different restriction enzyme digestion patterns, and in each clone a different fragment hybridizes to pSA38. The fourth, $\lambda S A 22$, may be allelic to $\lambda \mathrm{SA} 16$, since they both share similar restriction enzyme patterns; however, these similarities may have arisen from a gene duplication. One of the genomic clones, $\lambda S A 11$, contains two actin genes, separated by about 8 kilobases of spacer DNA. Other workers screening the same library have found at least two other actin genes which appear to be non-identical and non-allelic to ours [17]. Thus, at least six different actin genes have now been identified in this organism.

The actin gene family is being studied in a large number of systems and a fascinating story of the organization, evolution and expression of these genes is beginning to emerge. In contrast to the globin genes, the number of actin genes varies widely throughout phylogeny. At the extremes, yeast has only 1 actin gene $[13,14]$, while Dictyostelium has greater than 17 [8]. There are few data which address the issue of which actin genes are actually transcribed and, although it is possible that actin pseudogenes may exist in some organisms, the reason for the heterogeneity in actin gene number is unclear. The number of actin genes in sea urchin has been variously estimated at $5-20,10$ and $5[15,16,17]$.

A second aspect of actin gene evolution which appears to contrast with the globin family is conservation of placement of intervening sequences. Whereas in the globin genes, as well as others, the position of introns tends to be highly conserved during evolution, in actin genes intron position varies. This variation is seen both between species and between different actin genes within a species. Dictyostelium actin genes have no introns $[8,27]$. Three different intron locations have been reported in different Drosophila actin genes $[11,12]$, whereas yeast has an intron in yet a different position relative to the amino acid sequence $[13,14]$. Two introns, at positions 121 and 204 in the amino acid coding sequence, have been reported in two sea urchin actin genes [16, 17]. The data presented here concur in the placement of these introns in $\lambda S A 11, \lambda S A 16$ and $\lambda S A 22$. The popular 'gene shuffling' hypothesis [28] is based on the observation that intervening sequences commonly occur between 'protein domains', and the position of those introns is conserved during evolution. The apparent heterogeneity in intron positions in the actin genes would appear to argue against that theory. An alternative view is that actin gene duplication and shuffling are ancient events and that the primordial common introns have been lost.

A third intersting feature of the actin coding family is chromosomal linkage and clustering of the genes. The genes of the globin family are tightly clustered and, in most systems studied, arranged in order of their developmental expression. In contrast, the arrangement of the actin genes varies in phylogeny. At the extremes, at least some actin genes are closely linked in Dictyostelium [27], whereas in Drosophila the six actin genes are widely separated and scattered on different chromosomes $[11,12]$. The case of sea urchin may represent a third pattern, since the two genes in $\lambda$ SA1 1 are linked but separated by about 8 kilobases of DNA (Figs. 3 and 5). If all or most of the sea urchin actin genes occur with this spacing, it is not surprising that most of the genes isolated from the library are on different $\lambda$ clones. Isolation of the actin-containing clones from the same library in another laboratory has revealed a second pair of linked genes with about the same spacing as found in $\lambda$ SA1 1, but with very different restriction sites [17]. Thus it is possible that many or all actin gene family members are clustered together in the sea urchin. If this were the case, then the family would extend over 50-150 kilobases of DNA.

In summary, actin gene number, intron position and gene clustering vary greatly in different organisms. The relationship of this variation to the evolution and control of expression of this family remains to be determined.

\section{Acknowledgements}

We would like to thank $C$. Rushford for her help in the preparation of the heteroduplexes, J. Bernstein for preparing the illustrations and J. Langmore and J. Workman for their generous donation of materials and time on the electron microscope. This work was supported by NSF Grant PCM 78-15300 and NIH Training Grants HD-07048, GM-07544 and GM07315. 


\section{References}

1 Pollard, T.D. and Weihing, R.R. (1974) CRC Crit. Rev. Biochem 2, 1-65

2 Garrels, J.I. and Gibson, W. (1976) Cell 9, 793-805

3 Whalen, R.G., Butler-Brown, G.S. and Gros, F. (1976) Proc. Natl. Acad. Sci. U.S.A. 73, 2018-2022

4 Storti, R.V. and Rich, A. (1976) Proc. Natl. Acad. Sci. U.S.A. 73, 2246-2250

5 Rubenstein, P.A. and Spudich, J.A. (1977) Proc. Natl. Acad. Sci. U.S.A. 74, 120-123

6 Vandekerchove, J.A. and Weber, K. (1978) Proc. Natl. Acad. Sci. U.S.A. 75, 1106-1110

7 Storti, R.V., Horovitch, M.P., Scott, A.R. and Pardue, M.L. (1978) Cell 13, 589-578

8 Kindle, K.L. and Firtel, R.A. (1978) Cell 15, 763-780

9 Merlino, G.T., Water, R.D., Chamberlain, J.P., Jackson, D.A., El-Gewely, M.R. and Kleinsmith, L.J. (1980) Proc. Nat1. Acad. Sci. U.S.A. 77, 765-769

10 Tobin, S.L., Zulauf, E., Sanchez, F., Craig, E.A. and McCarthy, B.J. (1980) Cell 19, 121-131

11 Fyrberg, E.A., Kindle, K.L., Davidson, N. and Sodja, A. (1980) Cell 19, 365-378

12 Fyrberg, E.A., Bond, B.J., Hershey, N.D., Mixter, K.S. and Davidson, M. (1981) Cell 24, 107-116

13 Gallwitz, D. and Sure, I. (1980) Proc. Natl. Acad. Sci. U.S.A. 77, 2246-2250

14 Ng, R. and Abelson, J. (1980) Proc. Natl. Acad. Sci. U.S.A. $77,3912-3916$
15 Cleveland, D.E., Lapata, M.A., MacDonald, R.J., Cowan, N.J,, Rutter, W.J. and Kirschner, M.W. (1980) Cell 20, 95-105

16 Durica, D.S., Schloss, J.A. and Crain, W.R. (1980) Proc. Natl. Acad. Sci. U.S.A. 77, 5683-5687

17 Schuler, M.A. and Keller, E.B. (1981) Nucl. Acid. Res. 9, 591-604

18 Engel, J., Gunning, P.W. and Kedes, L. (1981) Proc. Natl. Acad. Sci. U.S.A. 78, 4674-4678

19 Merlino, G.T., Water, R.D., Moore, G.P. and Kleinsmith, L.J. (1981) Dev. Biol. 85, 505-508

20 Maniatis, T., Hardison, R.C., Lacy, E., Laurer, J., O'Connell, C., Quon, D., Sim, G.K, and Efstratiadis, A. (1978) Cell 15, 687-701

21 Rigby, P.W.J., Dieckmann, M., Rhodes, C. and Berg, P. (1977) J. Mol. Biol. 113, 237-251

22 Benton, W.D. and Davis, R.W. (1977) Science 196, 180182

23 Helling, R.B., Goodman, H.M. and Boyer, H.M. (1976) J. Virol. 14, 1235-1244

24 Southern, E.M. (1975) J. Mol. Biol. 98, 503-517

25 Davis, R.W., Simon, M. and Davidson, N. (1971) Methods Enzymol. 21, 413-428

26 Overbeek, P. (1980) Ph.D. Thesis, University of Michigan

27 McKeown, M., Taylor, W.C., Kindle, K.L., Firtel, R.A., Bender, W. and Davidson, N. (1978) Cell 15, 787-800

28 Gilbert, W. (1978) Nature 271, 501-508

29 Ullrich, A.J., Shine, J., Chirgwin, J., Pictet, R., Tischer, E., Rutter, W.J. and Goodman, H.M. (1977) Science 196, 1313-1319 